\title{
A classe média vai ao paraíso: representações no cinema da retomada
}

Maria Gabriela Silva Martins da Cunha Marinho ${ }^{1}$ Werick Vinicius Andrella², João Elias Nery ${ }^{3}$ 


\section{Resumo}

O artigo analisa as representações da classe média no cinema da retomada, tomando como exemplos os filmes Cronicamente inviável, Salve Geral!, Carandiru e O invasor. A análise identifica os valores desse segmento social, sua autoimagem e a transposição destas para as obras cinematográficas. Tem como referência a formação da classe média no Brasil a partir do século XIX, sua trajetória ao longo do século XX e início do XXI, bem como seus diferentes posicionamentos ideológicos, políticos e sociais.

Palavras-chave

Cinema brasileiro, cinema da retomada, cinema, classe média.

\section{Abstract}

The article analyzes the representations of the middle class in cinema da retomada (retaken cinema), taking as examples the movies Cronicamente inviável, Salve Geral!, Carandiru e O invasor. The analyze identifies the values of this social segment, its self-image and the transposition of these cinematographic works. It has as reference the shaping of the Brazilian middle class from the $19^{\text {th }}$ century, its trajectory during the $20^{\text {th }}$ century and beginning of the $21^{\text {st }}$ century, as well as theirs different ideological, political and social positioning.

\section{Keywords}

Brazilian cinema, retaken cinema, cinema, middle class. 
O filme A classe operária vai ao paraíso, de 1971, dirigido por Elio Petri, é considerado um clássico do cinema político italiano. A história do filme se desenrola em torno de uma reivindicação por melhoria das condições de trabalho dos operários da fábrica B.A.M. A luta pela consecução das demandas é intermediada por uma união de sindicatos e por um grupo de estudantes que pretende uma aliança operária estudantil em prol da revolução. As disputas e conflitos levaram à revisão do sistema de quotas de serviço e à readmissão de um operário que havia sido demitido em virtude das reivindicações. Contudo, a vitória alcançada pelos operários está longe de ser considerada como revolucionária. Nesse sentido, o paraíso da classe operária, a revolução, não foi alcançado e permanece no sonho de Lulu, um operário inicialmente identificado com os valores dos patrões que mais tarde sonha que ele e seus companheiros teriam alcançado o paraíso.

Em comparação, guardando as especificidades do significado do paraíso para os operários, propomos a seguinte questão: a classe média teria alcançado o seu paraíso? Isto é, o crescimento histórico da classe média, sobretudo a partir da década de 1950 até a emergência da chamada nova classe média brasileira das primeiras décadas do século XXI, pode ser visto como o paraíso da classe média? Diante disso, a classe média despontou como um ator político? A década de crises que Hobsbawm afirma ter existido nos anos 1980 está vinculada com a violência crescente nos centros urbanos brasileiros. Como a classe média se relaciona com esse fenômeno socioeconômico? Essas questões norteiam esse trabalho, no qual analisamos dos filmes Cronicamente inviável, Salve Geral!, Carandiru e O Invasor, que apresentam diferentes construções do papel e das identidades da classe média, as quais nos interessam discutir no artigo. 


\section{A Classe média foi ao paraíso?}

Classe média: origens e trajetória

A noção de classe média adotada neste artigo parte da posição exposta por Boito Jr. (2004), recuperando o conceito de Saes (1985, p. 42) acerca da classe média. De acordo com Boito Jr., a classe média nada mais é que uma

Noção prática para indicar um comportamento político e ideológico específico gerado por uma 'consciência meritocrática', típico de um setor dos trabalhadores assalariados, comportamento esse que os distinguiria dos trabalhadores manuais (BOITO JR., 2004, p. 11).

As camadas médias urbanas situam-se, de acordo com Saes (1985, p. 42), "num duplo contexto histórico: consolidação do Estado Nacional até 1850; de outro, a expansão da economia cafeeira de São Paulo desde 1870". No primeiro movimento, houve a formação de um corpo burocrático civil e militar. Já no segundo, houve a necessidade de criação de um aparelho urbano de serviços anexos ao setor agrário-exportador. São Paulo e Rio de Janeiro foram os focos de novos grupos sociais. Décio Saes afirma que houve duas origens distintas. A primeira originou-se de ex-proprietários de terras que foram para a cidade por estarem passando por decadência social. Em virtude de seus laços familiares com a oligarquia do café - alusão ao histórico aristocrático -, obtiveram cargos públicos, cargos de gerência em empresas etc., um apadrinhamento pelas elites agrárias. Por outro lado, após 1870, trabalhadores rurais passaram a migrar em grande número para o centro-sul. Essa massa de trabalhadores desejava ascensão social. A composição dessa classe média ascendente é heterogênea e seu processo de crescimento está relacionado com o aumento das oportunidades de trabalho não-manuais, que, por sua vez, está atrelado ao crescimento da indústria e dos serviços gerados pelas demandas agroexportadores e industriais (SAES, 1975, p. 38).

Posteriormente a esses primeiros impulsos à criação da classe média, nas décadas de 1930-1940 gestaram-se transformações na constituição do 
aparelho burocrático e da economia em geral que propiciaram a emergência de uma burocracia econômica e militar importante na construção da classe média, como demonstra Quadros (1985, p. 36-37). Tais fenômenos estão diretamente ligados à Revolução de 1930, à ampliação do aparelho de Estado e à crescente urbanização do país, que exigiu cidadãos com maior escolaridade e habilidades típicas de uma sociedade industrial, urbana e de massas, já existente em países da Europa desde o século anterior.

Com a gestão de Juscelino Kubitschek na presidência da república (19551960) e seu Plano de Metas, o Brasil viveu forte crescimento econômico, com acelerado processo de industrialização e criação de infraestrutura, sobretudo rodoviária. A economia ganhou força e, com ela, uma nova ascensão da classe média, agora com novos contornos, uma vez que estava intimamente relacionada com as estruturas da divisão social do trabalho do capitalismo monopolista (QUADROS, 1985, p. 27). Com o avanço do capitalismo e de novos processos de produção e organização da força de trabalho, a educação começa a se destacar como uma espécie de mola propulsora à ascensão social. "A educação só funciona como veículo para o sucesso enquanto as necessidades ocupacionais de uma sociedade exigem pessoas instruídas" (MILLS, 1979, p. 288). Foi o caso do Brasil, onde a educação passou a ser uma maneira de se ingressar no emprego público, que ganha destaque. A ascensão via escolarização no Brasil é abordada por Miceli (2001). Ao analisar a trajetória de intelectuais oriundos de diferentes extratos sociais e regiões do país, o autor observa que, ao capital familiar, escritores, tecnocratas e políticos adicionaram o capital intelectual obtido em cursos tradicionais - principalmente o de bacharel em Direito - na construção das redes de sociabilidade que Ihes dariam a possibilidade de ocupar postos no aparelho de Estado e em órgãos de imprensa e da cultura que se estabelecia.

Entre 1950 e 1970, houve forte crescimento da classe média, sobretudo na década de 1970, quando a classe média constituía $31 \%$ do conjunto dos trabalhadores assalariados urbanos (QUADROS, 1985, p. 84). Esse é um dos resultados da política econômica implantada pelo regime civil-militar (1964- 
1985), que possibilitou "... a emergência da nova classe média, especialmente de seu segmento de altas rendas" (QUADROS, 1985, p. 51). Durante a década de 1970, a classe média do "Milagre Econômico", denominação amplamente disseminada para caracterizar a forte expansão da atividade econômica no Brasil entre 1971 e 1973, era principalmente inserida em altos cargos.

O "paraíso" da classe média foi a crescente mobilidade social, o crescente desejo de possuir status e de consumir, valores que impulsionaram a formação da sociedade de consumo. O boom experimentado pela classe média foi um fenômeno que repercutiu na hierarquização da sociedade, com uma camada média cada vez mais numerosa e influente na política nacional, relegando ao ostracismo o operariado. A explosão cultural das décadas de 1950 e 1960 foi claramente de classe média - um setor mais esclarecido da classe média. Uma classe média que possuía status, renda, que foi se expressando por meio da cultura. Ainda que fosse um setor mais progressista, suas bases remontam ao desenvolvimento da economia que propiciou o desenvolvimento dessa classe média.

O paraíso alcançado foi o ápice de autodiferenciação em relação ao operariado. A classe média se via como superior. A autoimagem da classe média foi criada e consolidada nesse lugar alcançado e a identificação social com a burguesia é central à compreensão desse lugar. A ideologia liberal da meritocracia era o discurso ideológico desse paraíso, que representava a manutenção da ordem, algo desejado pela classe média em seu conjunto. A existência de seu paraíso estava intimamente ligada à permanência do modelo econômico adotado. Em função disso, é possível afirmar que o paraíso da classe média foi constituído de uma ascensão social em larga escala fundamentada num modelo econômico excludente, ao mesmo tempo em que a ideologia que sustentava tal paraíso era conservadora e utilizava a ideologia meritocrática da classe média. Enquanto o crescimento da economia dava sustentação ao paraíso, a classe média usufruiu de seus benefícios. Mas essa classe média teve seu paraíso datado. Teve fim com as crises das décadas de 1980 e 1990. 
Longe do paraíso

Ao mesmo tempo em que houve essa mobilidade social e crescimento da classe média, a concentração de renda provocou aumento da desigualdade social. Nas décadas de 1980 e 1990, tal fenômeno social foi mais nitidamente sentido, especialmente pelo crescimento da violência. A crise no início da década de 1980 atingiu diretamente as pretensões de ascensão da classe média, na medida em que a educação não estava agindo como anteriormente em relação a ser uma força propulsora à ascensão social. Com isso, grande quantidade de novos titulados ingressantes no mercado de trabalho não foi absorvida. Segundo Bonelli (1989, p. 20), houve alterações no padrão de consumo e estilo de vida, ao mesmo tempo em que houve mudanças nos valores, visão de mundo e identidade social. Segundo esta autora, houve três mudanças principais:

1) A percepção da existência de um contexto socioeconômico interferindo nas oportunidades de vida de cada um;

2) A necessidade de construir uma identidade coletiva mais segura, baseandose na solidariedade entre os que são semelhantes;

3) Uma conjuntura política de "abertura", que minimizava os custos de ações coletivas diante de insegurança gerada pelas ameaças à estratificação por status.

Com tais mudanças, a classe média passou a se organizar politicamente com o propósito de garantir os privilégios que havia conquistado nas décadas anteriores. Nesse contexto, a mobilização da classe média no período foi motivada pela percepção de que o "paraíso" conquistado estava ameaçado e, portanto, haveria forte tendência a que ocorressem perdas em suas posições na hierarquia social. O contexto socioeconômico foi apenas um diminuidor dos custos de ação coletiva e uma espécie de pretexto político (BONELLI, 1989, p. 56). O movimento das Diretas Já pode ser visto sob esse prisma. 
A classe média foi um ator social na medida em que almejava manter aquilo que Ihe era caro, o status, a autoimagem, uma identidade social. O medo de decadência social fez da classe média um ator político ressentido com o cenário econômico. Sua mobilização, portanto, foi orientada para reestabelecer o equilíbrio entre posição econômica e status social (BONELLI, 1989, p. 57-58). A movimentação política dos anos 1980 - movimentação para o fim da ditadura, as greves, as Diretas Já, a mobilização pela constituinte - foi, para a classe média, portanto, uma maneira de agir coletivamente visando a alcançar interesses próprios.

\section{A nova classe média}

Nas duas gestões de Luiz Inácio Lula da Silva (2003 a 2010), a classe média ascendeu devido ao aumento do salário mínimo e à política de classificação segundo grupos de renda. Segundo Ricci,

a nova classe média é muito distinta, em imaginário, em representação social, da classe tradicional de nosso país. É composta por quem não tem hábito de leitura e é absolutamente pragmático. Assim, valores universais e regras gerais são colocados sob suspeita com facilidade, a não ser que vinculados a valores religiosos (RICCI, 2010, p. 76).

Essa nova classe média está fortemente vinculada à religião, em detrimento de outros valores sociais e de sociabilidade. Não que isso não ocorresse antes, como em retrospectiva podemos verificar, por exemplo, na mobilização da classe média nos anos 1960 conhecida como "Marcha da família com Deus pela liberdade", contra propostas feitas pelo presidente João Goulart. A nova classe média se tornou descrente do processo político, olha com desconfiança para a política, agindo diante dela com pragmatismo, ou seja, busca apoiar propostas que a favoreçam, sem que estejam vinculadas a uma ideologia específica ou a um partido político. Podemos afirmar ainda que a classe média atual é possuidora da "ideologia da intimidade", que revela, segundo interpretação de Ricci (2010, p. 83), que o "o cidadão comum sentia-se gradativamente mais ressentido com autoridades e espaços públicos, mais excludentes, seletivos e competitivos". Partindo disso, a ação política desse grupo está associada à ação 
coletiva vinculada a associações religiosas (RICCI, 2010, pp. 79-80). Esse autor afirma que, desse modo, surgiu nessa classe média um movimento refratário em relação a "instâncias mais institucionalizadas e formais da política" (RICCI, 2010, p. 81). Assim, uma cultura anti-institucionalista - sendo também base legitimadora dos representantes religiosos, que possuem grande força política atualmente - foi sendo criada nessa nova classe média.

Comparada às classe médias dos anos 1950 e do "milagre", que possuíam referência nas elites econômicas até a crise dos anos 1980, alterando a autoimagem da classe média, a atual tem por referência a religião e não é instruída como foram as classes médias dos períodos anteriores. Durante o Governo Lula, foram criadas condições de ascensão social distintas daquelas. A nova classe média ascendeu no bojo da plataforma de governo de Lula, orientado pelo crescimento do mercado interno e da produção nacional.

Em relação a essa nova classe média, podemos afirmar que o paraíso foi distinto. Apesar de ser sustentada pelo crescimento da economia, ela foi criada por uma medida governamental. Atualmente, a classe média é quantificada tendo por base o novo critério brasileiro. Nele, a classe média é dividida em faixas de rendimentos. Segundo a Fundação Getúlio Vargas (FGV, 2013), as classes A e B possuem rendimentos acima de $R \$ 4.591$; classe $C$, entre $R \$ 1.064$ e 4.591; classe D, entre $R \$ 768$ e 1.064 ; classe $E$, abaixo de $R \$ 768$. Durante o Governo Lula, a classe média cresceu. Em 2005, correspondia a 43\% da população e, em 2008, a 53,8\% (RICCI, 2010). Ainda segundo Ricci (2010, p. 75), "desde 2002, a probabilidade de ascender da classe C para a Classe A nunca foi tão alta, e a de cair para a classe E nunca foi tão baixa". Em 2010, a classe média correspondia a 91,8 milhões de pessoas. Além disso, a FGV constatou que as classes A e B também passaram por crescimentos constantes no mesmo período.

A volta ao paraíso do qual havia sido retirada pela estagnação econômica dos anos 1980 e pela reestruturação do sistema produtivo foi, portanto, muito mais condicionada por medidas de um governo do que por uma conjuntura econômica favorável de crescimento industrial, como ocorrera nas décadas 
anteriores Além disso, podemos afirmar que o paraíso é vinculado ao consumo, diferentemente do que ocorrera antes. Hoje, mais do que naqueles períodos, a classe média tem relevância política. É uma parcela significativa da sociedade e alvo de diversas correntes ideológicas. Sua heterogeneidade histórica confirma essa constatação. Nas eleições que ocorreram a partir da ascensão de Lula à presidência, diversos candidatos de distintas origens ideológicas falaram diretamente à classe média. Os movimentos sociais do início dos anos 1980 e 1990 foram constituídos em grande parte por ela. Os novos movimentos sociais a têm em sua base e, portanto, a classe média é uma chave de compreensão fundamental do processo político brasileiro.

\section{A classe média no cinema da retomada}

Nas décadas de 1980 e 1990, a produção cinematográfica brasileira ganhou novos contornos e orientações; abriram-se outras possibilidades de representação/apresentação da sociedade brasileira; questões sociais reapareceram contextualizadas e foram inseridas temáticas e abordagens nas quais elementos não contemplados em obras de períodos anteriores passaram a aparecer.

A historiografia cinematográfica registra o movimento que houve a partir dos anos 1990 como "cinema da retomada". Segundo essa interpretação, teria havido uma ruptura no sistema de produção de filmes no Brasil em função do fim do modelo de financiamento adotado pelo Estado e praticado por meio da Embrafilme. De acordo com Marson,

O Cinema da Retomada se refere ao mais recente ciclo da história do cinema brasileiro, surgido graças a novas condições de produção que se apresentaram a partir da década de 90 , condições essas viabilizadas através de uma política cultural baseada em incentivos fiscais para os investimentos no cinema. A elaboração dessa política cinematográfica alterou as relações entre os cineastas, e, simultaneamente, exigiu novas formas de relacionamento desses com o Estado, seu principal interlocutor (MARSON, 2006, p. 11). 
Os filmes abordados neste artigo - Cronicamente inviável, Salve Geral!, Carandiru e O Invasor - fazem parte desse contexto de produção e circulação do filme brasileiro e têm imbricação com o processo político e social vivido no país a partir do final da ditadura civil-militar. São obras audiovisuais nas quais somos confrontados com representações do passado e do presente do país. A classe média, principal público do cinema no Brasil, viu-se representada em diferentes circunstâncias, por cineastas eles mesmos membros dessa classe e que procuraram apresentar personagens com o perfil desse grupo em situações próximas àquelas vividas no cotidiano, com interpretações muitas vezes contundentes e críticas ao comportamento sempre pronto a obter vantagens em função de uma suposta superioridade de classe.

\section{Cronicamente inviável?}

As imbricações entre contexto econômico e posicionamento da classe média são abordadas no filme Cronicamente Inviável, dirigido por Sérgio Bianchi. Lançado em 2000 em circuito restrito das cidades de São Paulo e Rio de Janeiro, o filme apresenta um Brasil marcado pela crise dos anos 1980 e pelo processo de "decadência" social da classe média oriunda das décadas de 1950-1970. Além disso, a questão da hierarquia social como elemento de organização da sociabilidade fica evidente. A classe média, representada no filme por Maria Alice, Luis, Amanda e Carlos, legitima em suas ações cotidianas o ideário de superioridade perante os grupos por ela considerados socialmente inferiores.

O cinismo, a abordagem do jeitinho brasileiro e de aspectos que fariam parte da identidade nacional são tratados por tais personagens de forma a ilustrarem uma legitimação do discurso ideológico de exclusão social. A contradição social como uma questão de estilo resume a maneira cínica de tratar os problemas sociais. Isso fica evidente, por exemplo, nas cenas de meninos que foram retirados da rua e colocados para tocar instrumentos de percussão e se apresentar aos turistas, nas quais o narrador diz que a exploração da miséria 
como atração turística, como ocorre na situação descrita, seria uma forma de fazer com que a miséria fosse necessária e desejável a tais possibilidades.

Conflitos urbanos também são abordados. O preconceito contra o nordestino aparece como uma justificativa paulistana para que se possa eximir de qualquer responsabilidade, seja ela dos governos ou do cidadão. O estereótipo aparece como legitimação de ações violentas contra determinados grupos sociais: negros, pobres, indígenas. Há interiorização e naturalização da violência como medida de ação. É o ritual sistematizado de agredir sempre o mais fraco e vulnerável socialmente. Não há mais a identificação de um agente político, mas indivíduos que compõem uma sociedade habituada à exclusão e à desigualdade, ao preconceito, ao cinismo e aos interesses individuais.

Não se trata de uma representação de uma realidade para fins de transformações, mas um retrato de uma época de descrença. O cinema, nesse caso, produz uma representação desencantada, em função de uma leitura da realidade pautada pela atitude crítica que recusa, de um lado, a mistificação e o otimismo e, de outro, o saudosismo e o pessimismo descompromissado. Exibido para integrantes da classe média esclarecida, que tende a criticar os segmentos dessa classe que privilegiam o consumo e valores individualistas, o filme insere-se na ideologia dessa fração da classe média que se vê como tal, mas se considera superior àqueles que abandonaram valores como ética, solidariedade e respeito pela diversidade.

Parte do que foi retratado ficcionalmente no filme está presente no comportamento da "nova classe média" impulsionada pelo governo Lula. Além disso, retomando a análise de Mills (1979), na qual a classe média constituiu o elemento, o elo de estabilização social, é possível identificar no filme traços do papel da classe média de consumir, contribuindo para a dinamização da economia, ao mesmo tempo em que equilibra as tensões entre as classes superiores e inferiores. Uma camada social marcada pelo pragmatismo e por desconfiança e descrença nas instituições políticas e na política de maneira geral. 
A partir dessas considerações, podemos tomar Cronicamente Inviável como um dos principais filmes dessa nova geração no sentido de diálogo com o passado e com o presente. Enfim, um relato de um diretor que não se contenta com o presente, mas que não vê esperança para o futuro. A ruptura com as propostas do Cinema Novo e das formas de transformações da sociedade brasileira são abandonadas em prol de um relato cujo foco é uma sociedade e uma classe social que representam o que de mais reacionário existe. A mudança de mentalidade é explícita e evidente. Cronicamente Inviável é um filme que ilustra essa ruptura com os valores anteriormente atribuídos à classe média e compõe, juntamente com outras obras cinematográficas, uma reflexão acerca da identidade contemporânea da classe média no Brasil.

\section{Carandiru: representações da violência}

O filme Carandiru é um retrato de uma experiência pessoal do médico Drauzio Varela naquele presídio antes da chacina de 1992. A violência é central nessa obra e pode ser relacionada à ideia da "década de crises", os anos 1980. Num país no qual o abismo social é enorme, uma crise econômica é sentida intensamente pelos grupos sociais mais vulneráveis. Num contexto de desemprego e de falta de perspectiva, a violência e o crime aparecem como uma maneira de suprir as necessidades dessas populações.

Dirigido por Hector Babenco e lançado em 2003, Carandiru está entre os filmes nacionais de maior público, com mais de 4,6 milhões de espectadores. Como noticiou a imprensa à época, o filme levou ao cinema pessoas que não consomem regularmente esse tipo de produção cultural, motivadas pela temática do filme, lançado dez anos depois do massacre do Carandiru, a partir do relato de Drauzio Varela, autor do livro utilizado como base para o roteiro do filme, nas telas da TV Globo e pela participação no filme de atores dessa emissora.

Diante de uma situação de insegurança crescente, exige-se maior atuação policial, mais rigor. O ocorrido em 1992 foi uma expressão dessa demanda. A insegurança, o temor, o descolamento da classe média com o sofrimento e as 
mazelas vividas pelas classes sociais mais vulneráveis, vivendo em condições precárias, remetem ao comportamento da classe média nas décadas de 1980 e 1990. A ideia de se eliminar o problema social pela eliminação dos que cometem delitos é a expressão mais explícita do reacionarismo da classe média. A eliminação das vítimas de um sistema econômico e social excludente significa uma higienização social. O tratamento dado aos presidiários é visto como merecido em virtude de seus delitos. A morte de presidiários é encarada como uma maneira de se livrar a sociedade de uma população indesejada, sem se ter em consideração a conjuntura e o contexto social que levam ao crime. Carandiru representa esse movimento de classe média.

O filme aborda o tema da violência pelo olhar de um médico que atuou no maior presídio à época e o discurso construído não atende inteiramente às expectativas da classe média expostas no parágrafo anterior. Tanto o livro quanto o roteiro do filme e, ainda, as interpretações dos atores, destacam aspectos humanos dos presos, apresentam suas histórias com certa idealização e fazem parte da cena até mesmo manifestações de solidariedade e de carinho, como o casamento entre dois presidiários, sendo que a "noiva" é representada pelo ator Rodrigo Santoro, talvez o mais conhecido, dentre o elenco da produção, do público em geral por suas participações em novelas da TV Globo. Mesmo a invasão pela Polícia Militar é retratada como violenta e excessiva.

Esse episódio, difundido pela mídia como "massacre do Carandiru", ainda está em aberto. O julgamento dos que participaram dele, do governador do Estado aos policiais que entraram no presídio, ocorreu em 2013, vinte anos depois do evento, e ainda não foi concluído. É possível que hoje os valores reacionários tenham maior presença entre a classe média, e que aquele olhar do médico seja considerado romântico e distante da realidade.

\section{Salve geral! - uma cidade sitiada}

Salve Geral! trata da violência urbana sob o olhar de quem comete o crime. Aqui, a centralidade é dada a uma organização, maior do que o indivíduo 
que comete o delito. O filme mostra a ação da organização dentro de um presídio. Apresenta o PCC - Primeiro Comando da Capital - como uma organização criada para representar o preso diante do sistema prisional. Cuidando da organização dos presos, o PCC age como uma espécie de guia de conduta aos associados. Tanto O Prisioneiro da Grade de Ferro quanto Salve Geral! mostram que certas práticas foram abolidas, como, por exemplo, o uso de crack e do estupro. O PCC visava a melhorar as condições de estadia no presídio. No filme, fica claro que havia duas correntes: uma focada na organização dos presos e na melhora das condições dos presídios; e outra, que tinha como tática de ação manter e guiar membros a cometerem crimes fora da prisão e realizarem atos contra os policiais. Tal divisão é apresentada pela divergência entre o personagem denominado Professor e outro líder.

A violência urbana no Brasil é uma questão muito profunda e complexa. Envolve fatores e condições socioeconômicas que estão relacionadas com o funcionamento e organização da estrutura social brasileira sob uma ordem econômica excludente e cruel. O cinema da retomada é responsável, entre outros fatores, por essa mudança de representação da violência urbana nos filmes brasileiros. Ainda vista como uma resultante do abismo social brasileiro, ela apresenta a figura da periferia em toda sua crueza, sem idealizações. A violência nas periferias, não só de São Paulo, mas em todo o Brasil, está intimamente ligada com a exclusão, com o preconceito, com a desigualdade, problemas que são abordados de maneira fria e crua nas obras da Retomada. Os filmes já citados, juntamente com Cidade de Deus e Notícias de uma guerra particular, por exemplo, são um retrato dessas condições, ainda que haja problemas quanto aos estereótipos sociais, pois retratam esse lado da violência e da realidade da periferia.

Em Salve Geral!, uma família de classe média é induzida a entrar no mundo do crime em decorrência das dificuldades financeiras vividas por seus membros. Essa família encontrou no crime a solução para seus problemas. A ação política está condicionada às decisões do PCC. No Cinema Novo, a periferia também era retratada em seus aspectos de pobreza e exclusão como parte 
das condições concretas de vida, mas violência não fazia parte do contexto. Os objetivos são outros. O meio de representação também. É retratada a crueza e a ambiguidade dessa realidade sem intenção de colocar uma ação política em perspectiva direta. Não existem anti-heróis, apenas personagens contraditórios e complexos de uma realidade complexa, que, no Cinema Novo, tendia a ser retratada com certa benevolência pelos produtores, eles mesmos integrantes da classe média engajada em uma cultura transformadora. Enfim, o foco da violência na Retomada é outro. A violência é moeda corrente e comum a todos.

\section{O Invasor}

A violência, no filme, é o tecido que une as partes numa rede que abraça toda a sociedade, circulando livremente entre os "termos díspares". A violência se tornou comum, naturalizada, aceita como moeda de troca. A mobilidade dos personagens entre as regiões - a mobilidade como um dos personagens centrais - de São Paulo expressa o quanto a violência está presente, seja na periferia, onde o personagem Anísio é rei, ou nos bairros nobres, nos quais moram aqueles que não fazem o serviço sujo, mas os que mandam e que contratam tais serviços ou utilizam de meios ilícitos para manter sua posição social. O diretor Beto Brant criou em O Invasor, filme exibido em 2002, um cenário em que a classe média vai à periferia da cidade de São Paulo em busca de auxílio para colocar em prática seus planos, criando vínculos surpreendentes entre cidadãos de diferentes posições sociais.

Segundo Oricchio (2003), em O Invasor, a realidade se apresenta no meio do caminho, nessa mobilidade que dá ao filme um elemento importante: a tentativa de representação de uma totalidade social através da mobilidade entre os termos díspares da cidade. A mobilidade representa o trânsito de indivíduos pela cidade, da violência caminhando livremente. Apesar dessa disfunção, o trânsito dos personagens e as relações que se estabelecem no filme evidenciam que a estrutura social permanece, ou seja, ainda que a violência tenha sido naturalizada e se tornado "denominador comum", ela não 
altera as estruturas sociais; cada qual permanece em sua classe; somente a violência tem o poder de permear o tecido social.

O personagem Anísio, no limite, ascende socialmente através do crime, já que em situações normais seria barrado por mecanismos sociais eficientes respaldados pelos aparelhos repressivos. Sabotage, outro personagem que no filme estabelece a relação entre centro e periferia, classe média e excluídos, é um exemplo de artista que foi barrado, que não decolou por sua origem social e não desfrutou de sua participação no filme em decorrência de conflitos entre gangues nas favelas paulistanas ${ }^{4}$. O filme traz para discussão a questão de como o brasileiro é visto. Numa espécie de reciclagem de Cronicamente Inviável, O Invasor rediscute a questão da corrupção, do "trambique", da falta de ética, da violência, praticadas pelos personagens Ivan e Gilberto, dupla de engenheiros, que faz o que é necessário para conseguir mais dinheiro. Os personagens representam a classe média paulistana, que vive na cidade em busca de privilégios e posição social, obtidos por meio de relações, por vezes, à margem da legalidade, tanto com os de sua classe, quanto com os que integram as periferias, utilizados por eles como mão de obra em atividades lícitas ou não. Estabelece-se um paralelo entre Ivan e Anísio enquanto personagens que desarrumam e desorganizam o arranjo da elite num elemento caótico. Ambos tratam da violência social, porém, o filme apresenta a violência na forma de relação de troca, numa aceitação cotidiana e natural.

\section{Considerações finais}

Os filmes analisados neste artigo - Cronicamente inviável, Salve Geral!, Carandiru e O Invasor - fazem parte do cinema da retomada. São filmes feitos pela e para a classe média, que tem a oportunidade de ver-se a si mesma retratada em diferentes aspectos. A classe média que vê esses filmes identifica-se com valores do que seria uma classe média tradicional (exceto 
no caso do filme Carandiru), formada até os anos 1970. Em oposição a esse padrão de filmes, há uma tendência à circulação de filmes brasileiros dirigidos a outros segmentos da classe média acostumados ao consumo televisivo sintetizado no "padrão Globo de qualidade" -, no qual se busca diversão fácil e nenhum compromisso social. Com dinheiro público obtido via financiamento ou renúncia fiscal, os agentes do campo cultural já inseridos no sistema de produção televisivo acessam verbas com as quais alimentam o mercado cinematográfico com comédias e dramas que utilizam o velho modelo descrito por Umberto Eco em Apocalípticos e integrados. Tanto a análise quanto os produtos continuam eficazes.

Como na indústria cultural tende-se a produzir aquilo que tem possibilidade de venda, de consumo, no caso cultural, filmes que procuram explicar o Brasil abordando com profundidade questões essenciais à nossa trajetória como povo e país continuam sendo produzidos, permanecendo restritos a circuitos frequentados pelos consumidores culturais de sempre. Entre os filmes analisados, essa diferenciação é nítida ao compararmos, por exemplo, o público de Carandiru - 2,6 milhões - e Cronicamente inviável - cerca de 30 mil espectadores. Se considerarmos o primeiro como parte de uma produção voltada à reflexão mais profunda sobre questões fundamentais da brasilidade, é preciso também indicar que dos quatro filmes incluídos nesse trabalho Carandiru é o único que teve ampla distribuição e atraiu público verdadeiramente de massa, levando ao cinema, como observamos, pessoas que não têm o hábito de consumir esse tipo de produção cultural, ficando restritas à televisão.

Violência, desigualdade social, conflitos urbanos e identidade do brasileiro são abordados em distintas obras acerca do que é o Brasil. Rupturas e novas óticas foram adotadas pelo cinema, num contexto de instabilidade econômica. Novos elementos e abordagens foram realizados. Mudanças significativas foram notadas. Os filmes analisados constituíram marcos de um período, retratos diferentes para uma mesma realidade, complexa, viva e em constante mudança. As análises dos filmes tratam das mudanças e novos meios de percepção 
da imagem do Brasil. Por fim, ainda que muito distintos entre si, os filmes contribuíram para uma composição fílmica que traz novas questões, polêmicas e interpretações acerca do Brasil, das identidades da população e de seus problemas. 


\section{Referências}

BOITO JR., A. "Classe média e sindicalismo". Primeira Versão, Campinas, n. 123, fev. 2004.

BONELli, M. da G. A Classe Média, do "Milagre" à Recessão. Monografia. Ideps/ Universidade de São Paulo, São Paulo, 1989.

MARSON, M. I. O Cinema da Retomada: Estado e cinema no Brasil, da dissolução da Embrafilme à criação da Ancine. Instituto de Filosofia e Ciências Humanas/ Universidade Estadual de Campinas, Campinas, 2006.

MELLO, J. M. C. de. "Prefácio". In: BELLUZZO, L. G. de M. O Senhor e Unicórnio. São Paulo: Brasiliense, 1984.

MILLS, W. C. A nova classe média. Rio de Janeiro: Zahar Editores, 1979.

MICELI, S. Intelectuais à brasileira. São Paulo: Companhia das Letras, 2001.

NAGIB, L. A Utopia no Cinema Brasileiro: matrizes, nostalgia, distopias. São Paulo: Cosac Naify, 2006. . O cinema da retomada: depoimentos de 90 cineastas dos anos 90. São Paulo: Editora 34, 2002.

ORICCHIO, L. Z. Cinema de novo: um balanço crítico da retomada. São Paulo: Estação Liberdade, 2003.

QUADROS, W. J. de. A nova classe média: 1950-1980. Dissertação (Mestrado). Instituto de Economia/Universidade de Campinas, Campinas, 1985.

RICCI, R. Lulismo, da Era dos movimentos sociais à ascensão da nova classe média Brasileira. Brasília: Fundação Astrojildo Pereira, 2010. 
SAES, D. "Classe média e políticas de classe: uma nota teórica". Contraponto, Rio de Janeiro, n. 2, nov. 1977.

. Classe media e política na Primeira República Brasileira (18891930). Rio de Janeiro: Vozes, 1985.

. Classe Média e Sistema Político no Brasil. São Paulo: T. A. Queiroz, 1985. 